\title{
PEMBENTUKAN KADER DETEKSI DINI RISIKO TINGGI KIA DENGAN MENGGUNAKAN KSPR DI NAGORI MOHO KECAMATAN JAWA MARAJA KABUPATEN SIMALUNGUN
}

\author{
Sri Hernawati Sirait ${ }^{1^{*}}$, Zuraidah $^{2}$, Sukaisi $^{3}$ \\ ${ }^{1-3}$ Poltekkes Kemenkes Medan \\ Email Korespondensi: hernarait.xxx@gmail.com \\ Disubmit: 19 Juli 2021 Diterima: 23 Juli 2022 Diterbitkan: 02 Februari 2022 \\ DOI: https://doi.org/10.33024/jkpm.v5i2.4696
}

\begin{abstract}
ABSTRAK
Kematian ibu dan bayi baru lahir masih menjadi masalah kesehatan masyarakat di Indonesia. Deteksi dini kehamilan dengan faktor risiko adalah kegiatan yang dilakukan untuk menemukan ibu hamil yang mempunyai faktor risiko dan komplikasi kebidanan. Kader kesehatan mempunyai peran besar dalam upaya meningkatkan kemampuan masyarakat menolong dirinya untuk mencapai derajat kesehatan yang optimal.Tujuan pengabdian masyarakat ini adalah untuk peningkatan kemampuan kader dalam upaya deteksi dini, rujukan kasus resiko tinggi kesehatan maternal khususnya ibu hamil dan neonatal dalam rangka kesiapan dan kesiagaan komplikasi bagi ibu dan bayi baru lahir (KIA) melalui pelayanan kesehatan yang berbasis masyarakat. kegatan pengabdian masyarakat berupa pembentukan kader deteksi dini risiko tinggi KIA dengan menggunakan Kartu Skor Poedji Rochjati (KSPR) dilaksanakan April-Agustus 2017. Metode pelaksanaan berupa pembentukan kelas kader, pelatihan, demonstrasi dan evaluasi. Kegiatan pengabdian masyarakat berupa pelatihan diikuti oleh 20 orang kader pada Nagori Moho Kecamatan Jawa Maraja Kabupaten Simalungun. Sebelum dilakukan pelatihan yang dilakukan dalam empat sesi pertemuan terlebih dahulu diberi pre test mengenai topik yang akan dilatih dan setelah dilakukan pelatihan dan demonstrasi dilakukan post test. Kegiatan pengabdian masyarakat ditutup dengan praktek langsung di poskesdes dan penyerahan sertifikat bagi kader. Kegiatan pengabdian pembentukan kader deteksi dini resiko tinggi KIA dengan menggunakan KSPR berjalan dengan baik dan lancar dan telah dilaksanakan di 5 Posyandu di Nagori Moho, Kec. Jawa Maraja Kab. Simalungun.
\end{abstract}

Kata Kunci: Deteksi dini risiko KIA, Kader, Posyandu

\begin{abstract}
Maternal and newborn deaths are still a public health problem in Indonesia. Early detection of pregnancy with risk factors is an activity carried out to find pregnant women who have risk factors and obstetric complications. Health cadres have a big role in efforts to improve the community's ability to help themselves to achieve optimal health status. The purpose of this community service is to increase the ability of cadres in early detection efforts, referral of high-risk cases of maternal health,
\end{abstract}


especially pregnant and neonatal women in the context of readiness and preparedness for complications for mothers and newborns (KIA) through community-based health services. Community service activities in the form of forming cadres for early detection of high risk of $\mathrm{MCH}$ by using the Poedji Rochjati Score Card (KSPR) were carried out April-August 2017. The method of implementation was the formation of cadre classes, training, demonstrations and evaluations. Community service activities in the form of training were attended by 20 cadres at Nagori Moho, Jawa Maraja District, Simalungun Regency. Prior to the training, which was conducted in four meeting sessions, a pre-test was given on the topic to be trained and after the training and demonstration a post-test was conducted. Community service activities were closed with hands-on practice at the Posyandu and the delivery of certificates for cadres. Service activities for the formation of high risk early detection cadres of $\mathrm{MCH}$ by using KSPR went well and smoothly and have been carried out in 5 Posyandu in Nagori Moho, Kec. Java Maraja Kab. Simalungun.

Keywords: Early detection of MCH risk, Cadres, Posyandu

\section{PENDAHULUAN}

Status Kesehatan ibu dan anak di Indonesia saat ini masih jauh dari harapan, di tandai dengan masih tingginya Angka Kematian Ibu (AKI).Menurut Survey Demografi Kependudukan Indonesia (SDKI) pada tahun 2010 AKI sebesar 248/100.000 kelahiran hidup. Pada tahun 2012 AKI menjadi 225/100.000 kelahiran hidup. Dibandingkan dengan tahun sebelumnya angka ini memang mengalami penurunan (Riskesda, 2012).

Kematian ibu dan bayi baru lahir masih menjadi masalah kesehatan masyarakat di Indonesia. Dari hasil sensus penduduk tahun 2010 menunjukkan bahwa kematian ibu masih didominasi oleh penyebab langsung yaitu perdarahan, hipertensi pada kehamilan, infeksi, komplikasi nifas dan keguguran. Disamping itu kematian ibu juga dilatarbelakangi oleh rendahnya tingkat sosial ekonomi, tingkat pendidikan, peran perempuan, kondisi rumah tangga dan struktur sosial masyarakat serta faktor transportasi yang mengakibatkan keterlambatan dalam mengenali gejala dan tanda bahaya pada kehamilan, pengambilan keputusan serta tindakan pertolongan. Oleh karena itu masyarakat terutama ibu hamil perlu mendapatkan informasi tentang deteksi dini resiko tinggi dan pengenalan tanda bahaya pada kehamilan, persalinan dan masa nifas. Selain itu ibu hamil memerlukan persiapan yang matang untuk menghadapi proses kelahiran, baik berupa materi, kesiapan fisik dan mentalnya supaya bisa menentukan tempat kelahiran dan mengambil keputusan tindakan pertolongan yang tepat.

Pemerintah Indonesia telah banyak melakukan kebijakan dan berbagai upaya untuk menurunkan angka kematian ibu dan bayi, antara lain dengan kegiatan Gerakan Sayang Ibu (GSI), Strategi Menyelamatkan Persalinan Sehat (Making Pregnant Safer) dan penggunaan buku KIA.Untuk menurunkan Angka Kematian Ibu harus mensinergiskan beberapa program yang terkait mulai dari sejak saat 
Ibu hamil, melahirkan, bayi, balita, remaja, PUS sampai usia lanjut (Kemenkes RI, 2011).

Menurut perspektif medis, pelayanan antenatal merupakan rangkaian pemeriksaan ibu hamil yang harus memenuhi unsur K1 (kunjungan pertama pada tenaga kesehatan) hingga K4 (kunjungan keempat pada tenaga kesehatan). Unsur K1, K2, K3 hingga K4 ini adalah jumlah kunjungan lengkap ibu hamil pada bidan desa (tenaga kesehatan) yang diatur dalam periodisasi trimester usia kehamilan. Standar ini penting bagi bidan desa untuk memungkinkannya memantau kondisi kehamilan ibu sejak awal hingga memasuki bulan persalinan dan dapat menetapkan berbagai langkah antisipatif yang diperlukan sesuai dengan kondisi tersebut (Mandriwati, 2007).

Pemenuhan standar kunjungan antenatal lengkap ini tidak hanya masalah jumlah kunjungan yang minimal 4 kali selama hamil tapi terutama kunjungan yang terjadwal setiap trimester usia kehamilan. Pola kunjungan yang ideal adalah 0-2-2 atau minimal 2 kali pada trimester kedua dan 2 kali ditrimester ketiga. Pola lain yang dianggap lebih baik adalah 1-1-2 yaitu 1 kali pada trimester pertama, 1 kali pada trimester kedua, dan 2 kali pada trimester ketiga (Mandriwati, 2007).

Deteksi dini dan penanganan ibu hamil berisiko/komplikasi kebidanan perlu lebih ditingkatkan di masyarakat, dalam rangka itulah deteksi dini ibu hamil berisiko/komplikasi kebidanan perlu difokuskan kepada keadaan yang menyebabkan kematian ibu bersalin di rumah dengan pertolongan oleh dukun bayi juga oleh masyarakat atau tenaga non kesehatan yang tidak berwenang (Kemenkes RI, 2011).

Kader kesehatan mempunyai peran besar dalam upaya meningkatkan kemampuan masyarakat menolong dirinya untuk mencapai derajat kesehatan yang optimal. Kader juga berperan dalam pembinaan masyarakat di bidang kesehatan melalui kegiatan yang dilakukan di posyandu. Kader harus memiliki pengetahuan dalam mengenal masalah-masalah kesehatan dan mendeteksi dini ibu hamil berisiko. Pemerintah mengadakan program pelatihan kader untuk mempersiapkan kader agar mampu berperan serta dalam upaya mewujudkan derajat kesehatan masyarakat yang optimal (Melani N. dkk,2009).

Kader kesehatan desa adalah anggota masyarakat yang diberi keterampilan dasar untuk dapat menjadi mitra kerja dan perpanjangan tangan bidan desa dalam menjangkau sasaran pelayanan. Keterampilan dasar itu diantaranya mencakup pembekalan pengetahuan dasar mengenai sanitasi diri dan lingkungan, pengetahuan mengenai indikasi dasar kesehatan, pengetahuan dasar tentang identifikasi dini faktor resiko kehamilan pada ibu hamil yang dapat menjadi penyulit persalinan, pendataan reguler tentang sasaran program dalam hal ini ibu hamil dan bersalin serta pengetahuan yang memadai mengenai alir rujukan pada kasuskasus kehamilan risiko tinggi (Karwati, dkk, 2010).

Penelitian Pramono (2014), diperoleh ada hubungan signifikan antara pembinaan kader dalam mendeteksi dini resiko tinggi KIA dengan menggunakan KSPR meningkatkan penjaringan risiko tinggi ibu hamil di masyarakat. Salah satu upaya yang dapat dilakukan 
pemerintah dalam upaya menurunkan angka kematian ibu adalah melalui pemberdayaan masyarakat terutama kader kesehatan yang dapat secara aktif melakukan pencatatan dan deteksi dini resiko tinggi pada ibu hamil dengan menggunakan KSPR (Santi, 2017)

Pendekatan yang dilakukan dalam pengabdian ini adalah peningkatan kemampuan kader dalam upaya deteksi dini, rujukan kasus resiko tinggi kesehatan maternal khususnya ibu hamil dan neonatal dalam rangka kesiapan dan kesiagaan komplikasi bagi ibu dan bayi baru lahir (KIA) melalui pelayanan kesehatan yang berbasis masyarakat. Berdasarkan hasil wawancara dengan Bidan Desa di Nagori Moho terdapat 20 orang kader namun kader yang aktif hanya 15 orang saja dan pada para kader tersebut belum pernah dilakukan pelatihan yang berhubungan dengan deteksi dini risiko tinggi Kesehatan Ibu dan Anak.

Dengan melihat permasalahan di atas, perlu diketahui bahwa ketidaktahuan kader mengenai cara melakukan penghitungan skor resiko tinggi menjadi faktor yang menghambat deteksi dini resiko tinggi pada ibu hamil yang dapat dilakukan oleh kader kesehatan sehingga ibu hamil terlambat untuk mendapat penanganan yang adekuat terhadap faktor risiko yang dialami.

\section{MASALAH}

Deteksi dini kehamilan dengan faktor risiko adalah kegiatan yang dilakukan untuk menemukan ibu hamil yang mempunyai faktor risiko dan komplikasi kebidanan. Faktor risiko yang sering dijumpai pada ibu hamil diantaranya adalah primigravida kurang dari 20 tahun atau lebih dari 35 tahun, jumlah anak lebih daripada 4 orang, jarak anak terakhir dengan kehamilan kurang dari 2 tahun. Tinggi badan kurang dari $145 \mathrm{~cm}$, berat badan kurang dari $38 \mathrm{~kg}$ atau lingkar lengan atas (LLA) kurang dari $23,5 \mathrm{~cm}$, riwayat keluarga dengan kencing manis (DM), hipertensi, riwayat cacat kongenital dan kelainan bentuk tubuh (Kemenkes RI, 2011).

Kader merupakan orang terdekat yang berada di tengah-tengah masyarakat, yang diharapkan dapat memegang pekerjaan penting khususnya setiap permasalahan yang berkaitan dengan kesehatan.Salah satu upaya untuk mewujudkan masyarakat Indonesia yang sehat adalah dengan memberdayakan masyarakat atau kader yang bersedia secara sukarela terlibat dalam masalah-masalah kesehatan (Melani N. dkk,2009).

Pembentukan kader deteksi dini risiko tinggi KIA dengan menggunakan KSPR adalah pelatihan yang dilakukan pada kader kesehatan. Dengan pembentukan kader diharapkan kader kesehatan mengetahui tentang resiko tinggi dalam kehamilan, persalinan, nifas dan neonatus, mampu melakukan deteksi dini dengan penilaian dengan Kartu Skor Poedji Rochjati (KSPR) dan mampu melakukan rujukan pada kasus resiko. Tujuan dari pengabdian ini diharapkan kader mengerti mengenai faktor risiko KIA, dapat menggunakan KSPR sebagai alat untuk deteksi dini KIA di Posyandu serta kegiatan deteksi faktor risiko dilaksanakan di Posyandu di Nagori Moho Kecamatan Jawa Maraja. 
Lokasi Pengabdian Kepada Masyarakat di Posyandu di Nagori Moho Kecamatan Jawa Maraja.

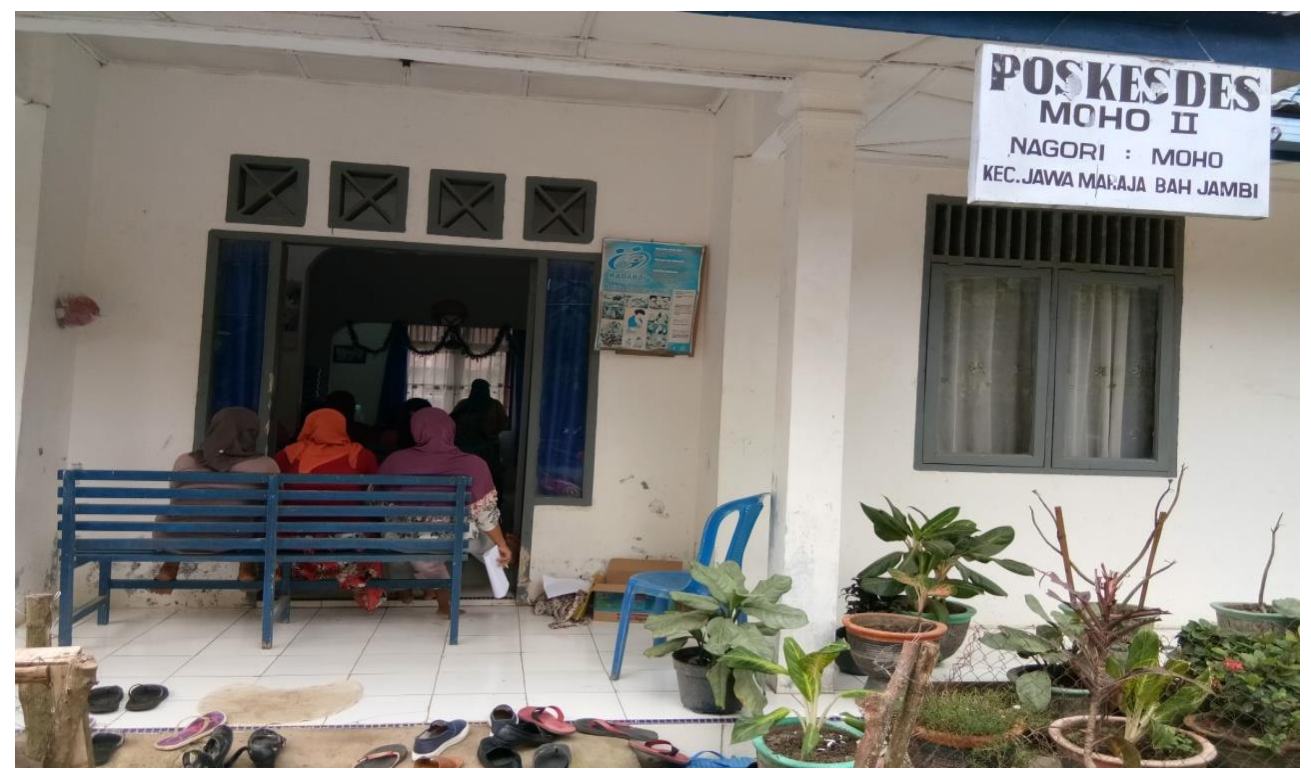

Gambar 1. Lokasi Kegiatan

\section{METODE}

Bentuk kegiatan pengabdian masyarakat berupa:

1. Tahap Persiapan

Tahap persiapan diawali persiapan dengan meminta izin ke pejabat pemerintahan setempat yaitu kepada Pangolu Nagori Moho Kec. Jawa Maraja Kabupaten Simalungun dan Kapus Jawa Maraja, melakukan sosialisasi pembentukan kader di Balai Desa, melakukan rekrutmen kader yang bersedia dilatih menjadi kader deteksi dini resiko tinggi (usia mulai $25 \mathrm{~s} / \mathrm{d} 45$ tahun, pendidikan minimal SMA dan telah menikah). Setelah didapatkan 20 orang kader yang bersedia dilatih maka dilakukan penjadwalan pelatihan yang bantu dan melibatkan bidan desa. Persiapan administrasi yaitu berupa materi penyuluhan, kuesioner pre test dan pos test, presensi setiap kegiatan serta kit sederhana yang berisi : materi 3 x pertemuan, kartu KSPR dan pena. Alat yang digunakan seperti : Laptop, LCD, Buku dan Kartu KSPR.

2. Tahap Pelaksanaan

Sebelum kegiatan pelatihan dimulai setiap kader mengisi daftar hadir terlebih dahulu. Kegiatan pelatihan ini dilaksanakan dalam 3 kegiatan dimana pada setiap kegiatan pelatihan kader diberikan kuesioner pre test untuk diisi sesuai dengan topik pelatihan yang akan dilakukan, dilanjutkan dengan pemberian materi, setelah selesai 1 kegiatan kader diberikan kembali kuesioner post test yang akan diisi. Pada kegiatan ketiga diadakan kegiatan bermain peran.

3. Tahap Evaluasi

a. Struktur

Kegiatan ini dilaksanakan oleh Tim Pengabdian Masyarakat Prodi D III Kebidanan Pematangsiantar Poltekkes Kemenkes Medan dengan jumlah 
peserta kader sebanyak 20 orang kader kesehatan di Nagori Moho Kec. Jawa Maraja Kab. Simalungun.

b. Proses

Proses kegiatan ini juga melibatkan bidan desa setempat, sehingga kegiatan dapat ini berjalan lancar sesuai dengan jadwal yang telah disepakati bersama dan smua kader sangat antusias dan aktif setiap melaksanakan kegiatan. Setelah hasil kuesioner dikoreksi dan semua kader dinyatakan lulus maka dilanjutkan dengan kegiatan demonstrasi di Posyandu Mawar dan Melati, dimana kader secara langsung melakukan pengisian KSPR pada ibu hamil, pada saat ini dilakukan evaluasi pengisian KSPR dengan menggunakan daftar cheklist.

Evaluasi kegiatan dilaksanakan 2 minggu setelah kegiatan pengabdian masyarakat berupa evaluasi langsung kegiatan pengisian KSPR oleh kader pada ibu hamil yang berkunjung ke Posyandu Mawar dan Melati. Kegiatan diakhiri dengan pemberian sertifikat pelatihan.

Rancangan evaluasi dilakukan dengan 2 kriteria penilaian, yaitu:

a. Untuk pengetahuan : menggunakan kuesioner pengetahuan dan nilai/ hasil post-test dengan point nilai minimal 75.

b. Untuk aplikasi: kader dapat melakukan deteksi dini resiko tinggi menggunakan KSPR dengan benar, minimal 2 minggu setelah demonstrasi yang dinilai sesuai dengan langkah-langkah pengisian KSPR.

c. Evaluasi akhir: Tindak lanjut dengan tetap dilaksanakannya deteksi dini resiko tinggi KIA oleh Kader Kesehatan di Nagori Moho Kecamatan Jawa Maraja Kabupaten Simalungun.

\section{HASIL DAN PEMBAHASAN}

Hasil pelaksanaan kegiatan pengabdian masyarakat ini dievaluasi berdasarkan kriteria pengetahuan dan aplikasi.

a) Pengetahuan kader dievaluasi melalui jawaban kuesioner dengan kriteria pengetahuan baik jika hasil/skor 76-100, cukup jika hasil / skor 56-75, dan kurang jika hasil /skor < 56 (Arikunto, 2006).

Tabel 1. Distribusi Pengetahuan Pre Test dan Post Test Kader Tentang Deteksi Dini KIA dengan menggunakan KSPR di Nagori Moho Kec. Jawa Maraja Kab. Simalungun

\begin{tabular}{|c|c|c|c|c|c|c|c|c|c|c|c|c|}
\hline \multirow{3}{*}{$\begin{array}{c}\text { Penge } \\
\text { tahuan } \\
\text { Kader }\end{array}$} & \multicolumn{4}{|c|}{ Pertemuan I } & \multicolumn{4}{|c|}{ Pertemuan II } & \multicolumn{4}{|c|}{ Pertemuan III } \\
\hline & \multicolumn{2}{|c|}{ Pre } & \multicolumn{2}{|c|}{ Post } & \multicolumn{2}{|c|}{ Pre } & \multicolumn{2}{|c|}{ Post } & \multicolumn{2}{|c|}{ Pre } & \multicolumn{2}{|c|}{ Post } \\
\hline & $f$ & $\%$ & $f$ & $\%$ & $f$ & $\%$ & $f$ & $\%$ & $f$ & $\%$ & $f$ & $\%$ \\
\hline Baik & 0 & 0 & 20 & $\begin{array}{r}10 \\
0 \\
\end{array}$ & 0 & 0 & 20 & 100 & 0 & 0 & 20 & 100 \\
\hline Cukup & 2 & 10 & 0 & 0 & 3 & 15 & 0 & 0 & 2 & 10 & 0 & 0 \\
\hline Kurang & $\begin{array}{l}1 \\
8\end{array}$ & 90 & 0 & 0 & 17 & 85 & 0 & 0 & 18 & 90 & 0 & 0 \\
\hline Total & $\begin{array}{l}2 \\
0\end{array}$ & 100 & 20 & $\begin{array}{r}10 \\
0\end{array}$ & 20 & 100 & 20 & 100 & 20 & 100 & 20 & 100 \\
\hline
\end{tabular}

Analisa Data : Dari tabel 1 dapat diketahui pada hasil penilaian awal (pre test) pertemuan I, II dan III dari 20 kader tidak ada yang memiliki 
pengetahuan baik tentang Deteksi Dini risiko tinggi KIA dengan menggunakan KSPR dan setelah dilakukan pemberian materi dilakukan penilaian kembali (post test) didapatkan seluruh kader sudah memiliki pengetahuan baik (100\%).

b) Aplikasi

Evaluasi/penilaian aplikasi diperoleh dari hasil redemonstrasi. Kader dapat melakukan deteksi dini risiko tinggi KIA dengan menggunakan KSPR dengan benar, minimal 2 minggu setelah demonstrasi yang dinilai sesuai dengan daftar checklist dan pengisian KSPR. Hasil demonstrasi di evaluasi melalui lembar check-list dengan kriteria aplikasi baik jika hasil praktek 76-100, cukup jika hasil praktek 56-75, dan kurang jika hasil praktek $<56$.

Tabel 2. Distribusi Hasil Demonstrasi Pengisian KSPR di Nagori Moho Kec. Jawa Maraja Kab. Simalungun

\begin{tabular}{llcc}
\hline No & Hasil Demonstrasi & f & $\%$ \\
\hline 1 & Baik & 20 & 100 \\
\hline 2 & Cukup & 0 & 0 \\
\hline 3 & Kurang & 0 & 0 \\
\hline & Total & 20 & 100 \\
\hline
\end{tabular}

Analisa Data : Dari tabel 2 dapat diketahui pada hasil demonstrasi melakukan deteksi dini risiko tinggi KIA dengan menggunakan KSPR seluruh kader (100\%) dapat melaksanakannya dengan baik.

Kegiatan pengabdian masyarakat berupa pembentukan kader deteksi dini risiko tinggi KIA dengan menggunakan KSPR dilaksanakan sejak 22 Mei04 Agustus 2017 di Nagori Moho Kec. Jawa Maraja Kab. Simalungun. Peserta pengabdian masyarakat dengan kegiatan pembentukan kader deteksi dini risiko tinggi KIA dengan menggunakan KSPR adalah kader kesehatan yang berdomisili di Nagori Moho yang merupakan lokasi pengabdian masyarakat. Kegiatan pembentukan kader deteksi dini risiko tinggi KIA dengan menggunakan KSPR dilaksanakan pada 20 orang kader kesehatan. Usia Kader yang menjadi peserta pengabdian masyarakat berkisar 26-45 tahun dengan latar pendidikan terakhir minimal SMA.

Kegiatan pengabdian masyarakat dimulai dengan pemberian kuesioner pre test mengenai deteksi risiko KIA dengan menggunakan KSPR, dilanjutkan dengan pemberian materi dari narasumber. Setelah pemberian materi dilakukan pengisian kuesioner post test. Kegiatan ini dilakukan pada pertemuan I, II dan III. Di akhir pertemuan ketiga dilakukan kegiatan bermain peran dimana kader dibagi menjadi 4 kelompok dan dari setiap kelompok dipilih kader yang berperan sebagai ibu hamil, kader, suami dan masyarakat. Setiap kelompok diberi kasus yang harus mereka perankan dan mengisi KSPR sesuai dengan kasus yang diberikan. Kegiatan pertemuan keempat dilakukan di Posyandu dimana kader diberikan kesempatan untuk mengisi kartu KSPR langsung pada ibu hamil yang diundang ke Posyandu. Kemudian hasil pengisian KSPR dinilai dengan menggunakan format checklist.

Selama kegiatan pengabdian masyarakat, kader dalam kondisi kooperatif, beberapa kader ada yang berinisiatif melakukan pengisian KSPR setelah pertemuan ketiga pada ibu hamil yang ada disekitar rumahnya dan dapat menentukan faktor risiko serta sudah dapat menentukan tempat 
rujukannya. Evaluasi kegiatan dilaksanakan 2 minggu setelah kegiatan pengabdian masyarakat berupa redemonstrasi dan kader tetap melaksanakan rutin kegiatan tersebut di Posyandu.

Peran kader memang sangat penting dalam menjembatani masyarakat khususnya kelompok sasaran posyandu. Berbagai informasi dari pemerintah lebih mudah disampaikan kepada masyarakat melalui kader. Karena kader lebih tanggap dan memiliki pengetahuan kesehatan diatas rata-rata dari kelompok sasaran posyandu (Naim Umar, 2008).

Penelitian Pramono (2014), diperoleh ada hubungan signifikan antara pembinaan kader dalam mendeteksi dini resiko tinggi KIA dengan menggunakan KSPR meningkatkan penjaringan risiko tinggi ibu hamil di masyarakat. Salah satu upaya yang dapat dilakukan pemerintah dalam upaya menurunkan angka kematian ibu adalah melalui pemberdayaan masyarakat terutama kader kesehatan yang dapat secara aktif melakukan pencatatan dan deteksi dini resiko tinggi pada ibu hamil dengan menggunakan KSPR (Santi, 2017)

Berdasarkan Profil Kesehatan Kabupaten Situbondo (2014) terjadi penurunan angka kematian ibu mealui upaya pemberdayaan masyarakat salah satunya adalah pendampingan lbu resiko tinggi oleh kader. Hasil penelitian Sugiarti, (2012) pemberdayaan kader menunjukkan pengaruh yang signifikan pada kemampuan untuk mendeteksi kehamilan resiko tinggi awal pada ibu hamil.

Kegiatan deteksi dini dan penanganan ibu hamil berisiko/komplikasi kebidanan perlu lebih ditingkatkan di masyarakat, dalam rangka itulah deteksi dini ibu hamil berisiko/komplikasi kebidanan perlu difokuskan kepada keadaan yang menyebabkan kematian ibu bersalin di rumah dengan pertolongan oleh dukun bayi juga oleh masyarakat atau tenaga non kesehatan yang tidak berwenang. Kader kesehatan mempunyai peran besar dalam upaya meningkatkan kemampuan masyarakat menolong dirinya untuk mencapai derajat kesehatan yang optimal. Kader juga berperan dalam pembinaan masyarakat di bidang kesehatan melalui kegiatan yang dilakukan di posyandu. Peran Bidan juga diharapkan agar dapat memfasilitasi kegiatan tersebut dalam setiap kegiatan Posyandu.

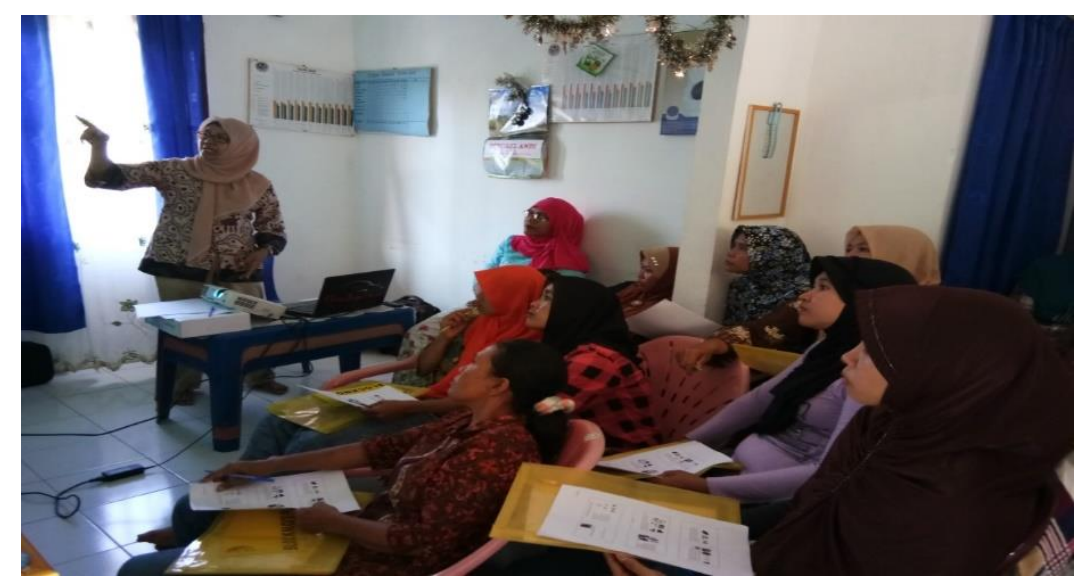

Gambar 1. Kegiatan ke- 1 


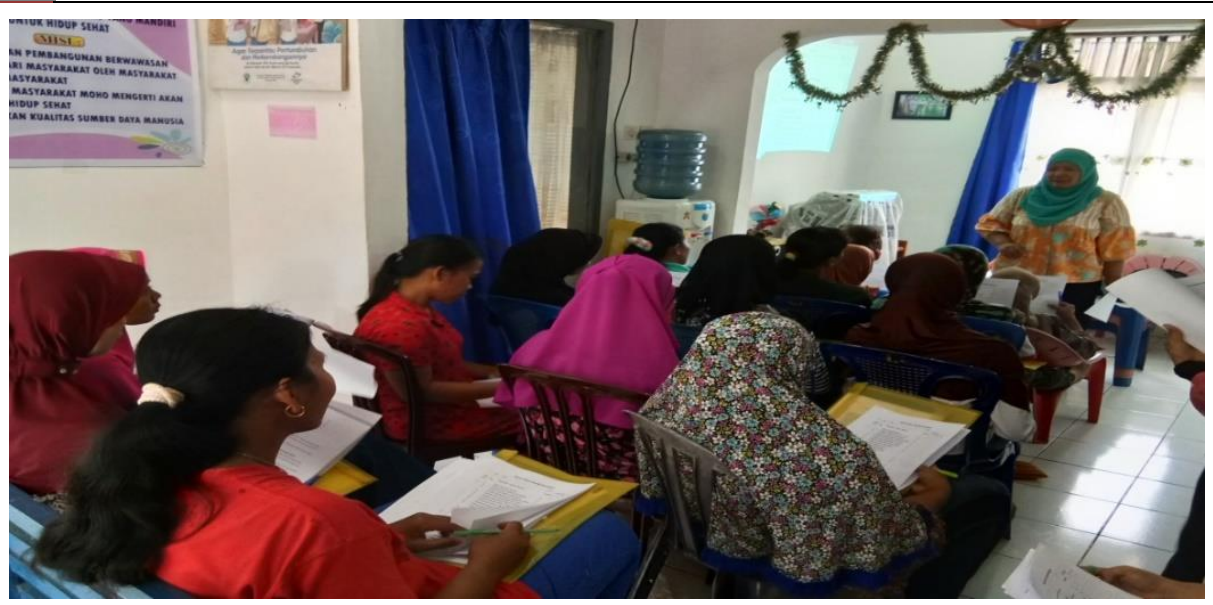

Gambar 2. Kegiatan ke- 2

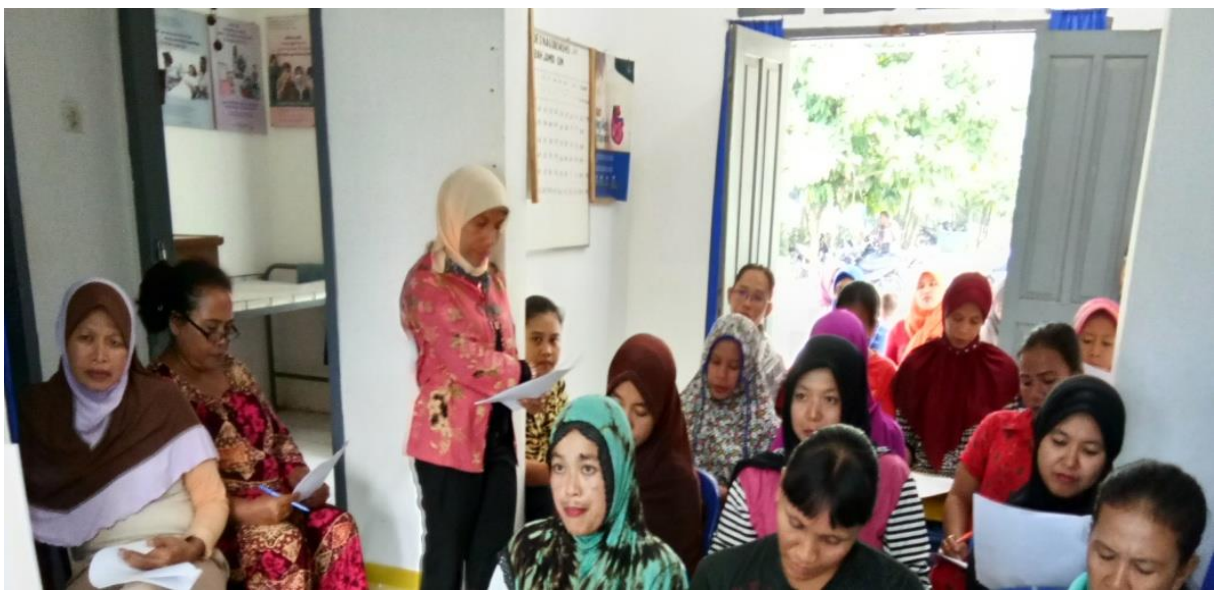

Gambar 3. Kegiatan ke- 3

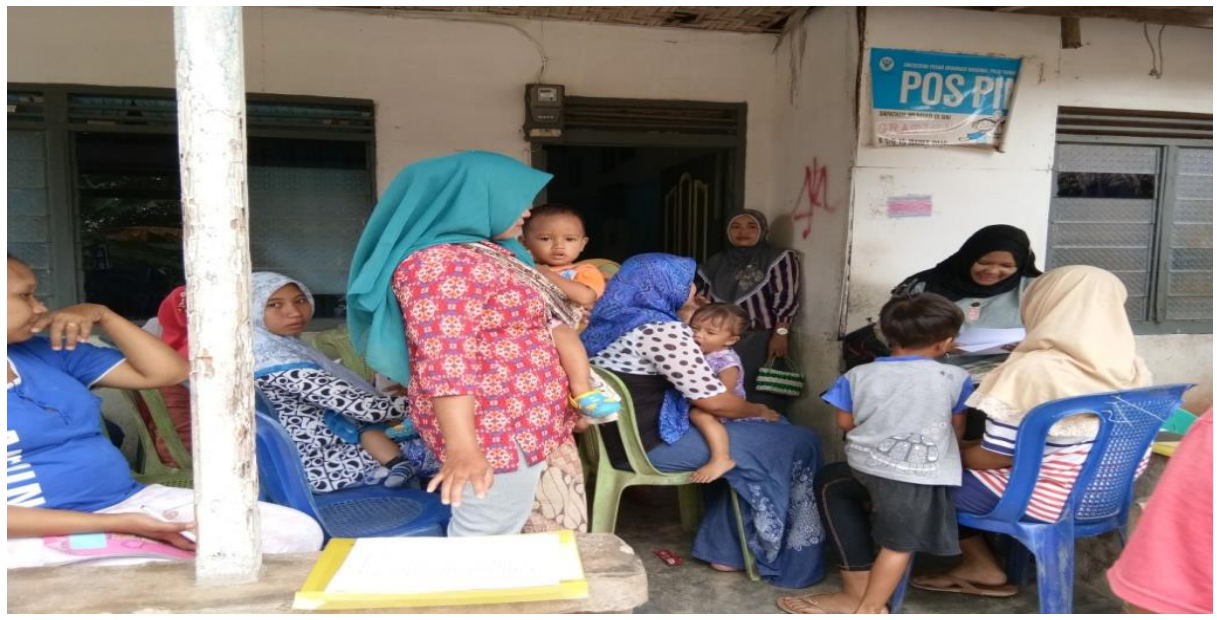

Gambar 4. Kegiatan ke- 4 


\section{KESIMPULAN DAN SARAN \\ Kesimpulan}

1. Pembentukan kader deteksi dini resiko tinggi $\mathrm{KIA}$ dengan menggunakan KSPR telah dilakukan pada kader sejumlah 20 orang

2. Kegiatan pengabdian pembentukan kader deteksi dini resiko tinggi KIA dengan menggunakan KSPR berjalan dengan baik dan lancar

3. Kegiatan deteksi dini resiko tinggi KIA dengan menggunakan KSPR yang dilakukan oleh kader telah dilaksanakan di 5 Posyandu di Nagori Moho, Kec. Jawa Maraja Kab. Simalungun.

\section{Saran}

1. Peran bidan memfasilitasi dan mengevaluasi agar kegiatan deteksi dini resiko tinggi KIA dengan menggunakan KSPR tetap dilakukan oleh kader.

2. Kader yang telah dibentuk agar dapat menjadi agent perubahan untuk menjadi sumber informasi mengenai deteksi $d$ ini resiko tinggi KIA dengan menggunakan KSPR dilingkungan tempat tinggal.

3. Peran Puskesmas ikut mendorong dilaksanakan pelatihan dan pembentukan kader deteksi dini resiko tinggi KIA dengan menggunakan KSPR agar terjadi penurunan yang signifikan Angka Kematian Ibu.

\section{DAFTAR PUSTAKA}

Arief, Mansjoer. (2010). Kapita Selekta Kedokteran, edisi 4, Jakarta : Media Aesculapius.

Karwati, dkk. (2010). Asuhan Kebidanan Komunitas, Jakarta, Salemba Medika

Kemenkes. (2011). Profil Kesehatan Indonesia 2012

Mandriwati. (2007). Penuntun Belajar Asuhan kebidanan Ibu hamil, Jakarta: EGC

Manuaba. (2010). IBG, Ilmu Kebidanan Penyakit Kandungan dan KB, 2010, Jakarta: EGC

Melani, N. dkk. (2009). Kebidanan Komunitas, Yogyakarta, Fitra Maya

Naim, Umar. (2008). Posyandu Upaya Kesehatan Berbasis Masyarakat, Yogyakarta, Kareso

Pramono. (2014). Pemetaan Determinan Angka Kematian Bayi di Jawa Timur Berdasarkan Indikator Pembangunan Kesehatan Masyarakat, ITS, Surabaya

Profil Kesehatan Kabupaten Situbondo. (2014). Jawa Timur: 2014

Pusat Data dan Informasi Profil Kesehatan Indonesia: 2013

Rochjati, Poedji. (2003). Skrining Antenatal Pada Ibu Hamil, Pengenalan Faktor Risiko Deteksi Dini Ibu Hamil Risiko Tinggi: Airlangga University Press, Surabaya.

Santi. (2017). Upaya penurunan Angka Kematian Ibu Melalui Pemberdayaan Masyarakat, Jurnal Oksitoksin Kebidanan, Volume IV.

Sugiarti. Dkk. (2012). Upaya Pemberdayaan Ibu Hamil Untuk Deteksi Dini Resiko Tinggi Kehamilan Trimester I, The Indonesian Journal of Public Health, Volume I. 